\title{
Dissemination and Breakthrough of Cartoon Culture under Television Media
}

\author{
Yanqing Cui \\ Shandong Binzhou University, Shandong Binzhou, 256600
}

Keywords: TV media; Animation culture; Communication channels; Path of development

\begin{abstract}
Animation, as a sunrise industry in the 21st century, contains infinite market opportunities. The animation industry represented by Japan, South Korea and the United States is an important pillar industry for its rapid social and economic development. In recent years, China's animation market has entered more and more countries, such as Japan, South Korea and the United States, while China's animation industry lacks strong competitiveness and vitality. Ultimately, it is not enough for China's animation culture to have an impact. Therefore, based on the development status of China's animation industry, this paper conducts an in-depth discussion on the cultural communication and industrial development of China's animation industry from the perspective of TV media communication.
\end{abstract}

As a cultural and creative industry, animation culture is created by combining modern technological means with profound culture. After various links such as creation, production, commercial packaging and acquisition of intellectual property rights, certain economic and social benefits can be created. TV media has certain advantages and obvious disadvantages in the communication of animation culture. Before China's reform and opening up, TV media was in an absolute marginal position in the media environment, and the household penetration rate of TV was still very low. However, after the reform and opening up, the popularity rate of TV has achieved $100 \%$, and with the popularity of TV, the role of TV media in society is more and more important. With the rapid development of the Internet, the Internet has become the preferred platform and medium for the public, and TV media is also on the road of integrating with new media technology. In the all-media era, TV media has been integrated and developed continuously with some new media such as the Internet and mobile phone terminals, providing users with more content services and better sharing and communication of resources. Under the support of new media technology, TV media also has a high degree of interactivity and diversity, realizing the strength and depth previously not available. Animation enterprises can not only spread their works by showing some films or short films on TV, but also not subject to the control of time, which greatly saves costs and expenses and reduces the risk brought by traditional media. In this way, it not only improves the attention and influence of animation, but also facilitates brand development and derivation.

Increasingly rich in new media environment, we need it to base on the actual, understand the current development situation of TV media, combined with the present situation of our animation culture dissemination to explore a new development direction.

\section{The development status and problems of the animation industry in China}

Compared with Japan, Korea and the United States, China's animation industry started relatively late. Since the 1970s, the animation industry in Japan and the United States has been developing vigorously, and exported a large number of excellent animation products to the world. According to a 2015 animation industry research report, the us, Japan and Korea account for the majority of China's huge animation consumer market, while China's domestic animation accounts for only $10 \%$. According to the survey report in China, $90 \%$ of the animation works favored by Chinese teenagers are Japanese and American animation works. In the development of animation industry. In addition to drawing on the successful development experience of the United States, Japan, Japan and other countries, it is necessary to be able to see clearly the current situation and problems, so as to explore the methods and ways for China's animation industry to achieve a virtuous cycle. Analyzing the 
reasons, the following problems exist in the development of China's animation industry:

\subsection{Focus on technology but ignore cultural connotation}

In recent years, China's animation industry has developed rapidly, but there is still some distance from the goal of animation power. This is because China's animation has no journey to complete an industrial chain, especially in the animation culture communication, the lack of a systematic marketing system. At present, the animation industry usually makes efforts in terms of technology, equipment and talent, but many animation products made with high-end technology and equipment are not successful in their communication. Further analysis of the reasons lies in the lack of content, no strong didactic, not high artistry. For animation, the core of the product is the content, animation without cultural connotation is not feasible. Compared to technology, it is only a tool to realize animation form.

\subsection{Inadequacy of that policy framework for the animation industry}

Transmission channel of the animation industry is mainly divided into media and new media, television media as a form of traditional media, has a large influence, time is long, high audience rate, etc, is one of the current our country family the highest penetration medium, in all the media convergence time is still a big mainstream media, but also the important channel of spreading anime culture. In recent years, the state administration of radio, film and television (sapprft) has increased the control of the broadcast proportion of domestic animation products and formulated a series of relevant protection policies and measures. With the opening of some exclusive channels for TV media, some excellent animation works have been quickly spread in China. But on the whole, China's animation industry is not yet mature in terms of market operation, and the country needs relevant policies and systems not too perfect. In addition, although China has a large number of animation works, they do not form their own characteristics, lack the essence of Chinese culture, and the ability of cultural communication is far from enough. At the present stage, the animation industry is still in the outsourcing stage from South Korea and Japan. My own animation works are still scarce, and there are not many leading animation enterprises in the true sense.

\subsection{Anime lacks depth and breadth}

With the continuous development of social media, the diversified value orientation also appears, and the communication between countries is also intensifying. People through the television media to see a variety of animation works, a variety of styles of animation works. As an important window to carry cultural communication, TV media is on the one hand a diversified invasion of animation culture, and on the other hand a deficiency of China's animation culture communication. It can be said that despite the rapid development of China's animation industry in recent years, various problems have arisen. For example, China's animation industry has insufficient exploration of China's rich cultural and historical resources, and the breadth and depth of many animation works need to be improved. Some animation enterprises have relatively weak media awareness, in the broadcast environment and post-broadcast earnings are subject to some restrictions, which greatly affect the return of enterprises.

\section{Analysis of animation culture communication strategy in China under TV media}

At present, the communication of China's animation culture still lags behind that of Japan, Japan, South Korea and other countries, which requires us to actively seek ways to promote cultural communication, make plans and strategies with our own advantages, and further shorten the animation development gap with Japan, the United States and South Korea.

\subsection{Establish correct market orientation}

Animation industry as a creative industry, the establishment of correct market guidance is the key. In the process of publicity, TV media should rely on the general goal of social development and disseminate social positive energy. While increasing the publicity of domestic animation, TV media 
should strengthen the examination of works and establish a perfect standard system of animation to ensure the healthy operation of the market. This is because most audiences of animation are teenagers. With the development of informatization, TV media, as the carrier of animation culture communication, plays an important role in animation culture communication. As an important audience of animation communication, the behavior and psychology of teenagers will be affected by communication. Therefore, in the process of introducing animation works, TV channels should pay attention to the control of animation content and quality, and resolutely eliminate and resist bad vulgar animation works. TV stations should strengthen the standardization and management of animation products.

\subsection{Digital media advantage}

The development of information technology has changed people's way of life, work and entertainment, bringing huge changes to all aspects of society. According to the 38th statistical report on the development of China's Internet network, as of June 2016, the number of Internet users in China has reached 710 million, and the Internet penetration rate in China has reached 51.7 percent, 3.1 percentage points higher than that of the world. The number of mobile Internet users has reached 656 million. The popularization and application of digital media technology brings a new development opportunity for China's animation culture communication. TV stations should seize this development opportunity, make use of the role and influence of digital media technology in communication, actively adapt to the new development situation of animation market, increase the communication of animation culture, give full play to the driving effect of digital technology in animation culture communication, and then realize the economic benefit and cultural value of animation culture.

\subsection{Perfect animation communication mechanism}

TV media in anime culture transmission, must base on the huge domestic market, set up scientific productions type classification system, and spread more rich comics, satisfy the audience's spiritual and cultural needs, establish and improve the animation market mechanism will be solid implementation of all aspects of the animation industry in China to promote our country form a complete, scientific animation industry chain, to make our country better to anime culture effectively to promote and spread.

\section{Conclusion}

The success of the communication of animation culture directly affects the communication effect and economic mechanism of the local animation works in China. Only on the basis of integrating the advantages of multi-media, and through a scientific market communication system, can TV media give animation its due cultural value and artistic value, thus gaining recognition in the domestic market. In addition, the animation culture with unique Chinese characteristics can be regarded as the competitiveness of the animation industry in the world to highlight the local identity of Chinese animation works, so as to better stimulate the development of China's animation culture and creative industry.

\section{References}

[1] Zhang Shaojiang, research on Chinese cultural industry competitiveness under the background of globalization [J], rural staff counselor, 2017 (21).

[2] LiuYi, study on interactive mechanism of animation industry under the background of new media [J], western radio and television, 2016 (7) :97-97.

[3] Yu Jianping, Sun Bingfeng, Lin Biyue, complementary assets and animation industry development: institutional obstacles and elimination -- taking cartoon channel as an example [J], western radio and television, 2016 (7) :97-97. 
[4] Tan Xiao, on the development of China's TV animation industry [J], contemporary TV, 2016 (5) :35-36

[5] Ji Xiaoyu, TV media characteristics and development strategies in animation industry chain [J], contemporary TV, 2016 (10): 102-103. 